\title{
Mutagenic Activity of Atmospheric Ultrafine Particles at a Roadside Site and a Suburban Site
}

\author{
Youhei Kawanaka, ${ }^{*, a, b}$ Emiko Matsumoto, ${ }^{a}$ Ning Wang, ${ }^{a}$ Yoshiteru Tsuchiya, ${ }^{a}$ Sun-Ja Yun, ${ }^{a}$ \\ Zhao Wu Jiang, ${ }^{b}$ and Kazuhiko Sakamoto ${ }^{b}$
}

${ }^{a}$ The Institute of Basic Environmental Research, Environmental Control Center Co., Ltd., 323-1 Shimo-ongata, Hachioji, Tokyo 1920154, Japan and ${ }^{b}$ Department of Environmental Science and Human Engineering, Graduate School of Science and Engineering, Saitama University, 255 Shimo-ohkubo, Sakura, Saitama 338-8570, Japan

(Received December 15, 2005; Accepted March 22, 2006)

\begin{abstract}
The mutagenic activity of size-fractionated atmospheric particulate matter (PM) was investigated at both a roadside site and a suburban site in Saitama, Japan. Sampling was carried out using a low-pressure cascade impactor between January and February 2005. The mutagenic activity of the size-fractionated PM was determined by the Ames test using Salmonella typhimurium strain TA98 without metabolic activation (S9). Most of the mutagenic activity was found in the fine particle fraction $(<2.1 \mu \mathrm{m})$ at both sites. There was almost no difference in the contribution of fine particles to the mutagenic activity of total PM between the two sites. On the other hand, there was a clear difference in the contribution of ultrafine particles $(<0.12 \mu \mathrm{m})$ to the mutagenic activity between the two sites. At the suburban site, ultrafine particles accounted for $5.7 \%$ of the mutagenic activity of total PM. In contrast, at the roadside site, ultrafine particles contributed as much as $12 \%$ to the mutagenic activity of total PM, although their contribution to the total PM mass was only $2.3 \%$. Moreover, the mutagenic activity per unit air volume in the ultrafine particle fraction at the roadside site $\left(1.2\right.$ revertants $\left./ \mathrm{m}^{3}\right)$ was 3.1 -fold higher than that at the suburban site $\left(0.38\right.$ revertants $\left./ \mathrm{m}^{3}\right)$, although the activity in the fine particle fraction at the roadside site was only 1.4 -fold higher than that at the suburban site. These results indicated that, with regard to mutagenicity, the health risk due to ultrafine particles is relatively high at roadside areas.
\end{abstract}

Key words — ultrafine particle, mutagenic activity, roadside, size distribution

\section{INTRODUCTION}

The particle size distribution of atmospheric particulate matter (PM) is very important with regard to the influence of PM on human health, because particle size controls the deposition behaviour of PM in respiratory organs. ${ }^{1,2)}$ Coarse particles are mainly deposited in the nasal area and the upper parts of the respiratory tract. In contrast, fine and ultrafine particles can easily reach the pulmonary alveoli. In particular, ultrafine particles are deposited at higher efficiency in the pulmonary alveoli than fine particles. ${ }^{1)}$ Moreover, some of the ultrafine particles that are deposited on the surfaces of pulmonary alveoli penetrate into cells and blood vessels of the lung. ${ }^{3,4)}$ In addition, it was recently reported that some of the

*To whom correspondence should be addressed: The Institute of Basic Environmental Research, Environmental Control Center Co., Ltd., 323-1 Shimo-ongata, Hachioji, Tokyo 192-0154, Japan. Tel.: +81-42-650-7228; Fax: +81-42-652-0800; E-mail: ykawanaka@kankyo-kanri.co.jp inhaled ultrafine particles were transported to the brain. ${ }^{5)}$ Therefore, ultrafine particles may act as carriers of chemicals that act as triggers for various health effects. However, at present insufficient information is available about the chemical composition and toxicity of ultrafine particles to draw any definite conclusions regarding their influence on human health.

PM contains various chemical substances and extracts of PM show mutagenicity. ${ }^{6-8)}$ Several authors investigated the concentrations of mutagenic compounds and mutagenic activities of PM fractionated according to size: the conclusion is that mutagenic compounds, such as polycyclic aromatic hydrocarbons (PAHs) and nitrated polycyclic aromatic hydrocarbons (nitro-PAHs), are mainly present in the fine particle fraction, ${ }^{9-12)}$ and most of the mutagenic activity is observed in fine particle fraction. ${ }^{10,13-15)}$ However, very little information is available about the mutagenic activity of ultrafine particles and their contribution to the total mutagenic activity. ${ }^{16,17)}$ In particular, there have been no reports 
regarding those in the ambient air at roadside areas, although ultrafine particles are generated mainly by combustion sources, such as motor vehicles. ${ }^{18)}$ Both the mutagenic activity and the mutagenic contribution of ultrafine particles are expected to be particularly high at roadside areas.

In the present study, we measured the mutagenicity of size-fractionated PM at a roadside site and a suburban site. The mutagenic activity of ultrafine particles and their contribution to the mutagenic activity of total PM at the roadside site were compared with those at the suburban site.

\section{MATERIALS AND METHODS}

Sampling Sites — PM sampling was performed at a roadside site and a suburban site. The roadside site was located within $1 \mathrm{~m}$ of the kerbside of Prefecture Road 57 in Saitama City, located to the north of Tokyo, Japan. The traffic flow at the site was about 19000 vehicles per day and the fraction of heavy vehicles was $21 \%$ of the total number of vehicles. The suburban site was located within Saitama University in the residential area in Saitama City and at a distance of $300 \mathrm{~m}$ from the roadside site.

Sampling and Weighing of PM — A low-pressure cascade impactor (LP-20, Dylec, Japan) was used to measure particle size distributions of mass concentration and mutagenic activity of PM at the roadside site and the suburban site. PM was separated into twelve fractions of different sizes as follows: $<0.12,0.12-0.20,0.20-0.30,0.30-0.50,0.50$ $0.70,0.70-1.2,1.2-2.1,2.1-3.5,3.5-5.2,5.2-7.8$, $7.8-11$, and $>11 \mu \mathrm{m}$. Sampling was carried out over 5 weeks from 24 January to 28 February 2005. PM was collected on quartz fibre filters (2500QAT-UP, Pallflex Products, U.S.A.) at a flow rate of $23.0 \mathrm{l} /$ min and the filters were changed every week.

PM mass concentration was determined by weighing the filters using a microbalance (M5P-F, Sartorius) before and after air sampling. The filters were equilibrated at a relative humidity of $45 \pm 5 \%$ and a temperature of $20 \pm 1^{\circ} \mathrm{C}$ in the weighing room for at least $48 \mathrm{hr}$ before weighing commenced. An alpha-particle source was used to eliminate the effects of static electricity on the weighing process. After the filters were weighed, they were stored at $-30^{\circ} \mathrm{C}$ in a freezer until extraction.

Pretreatment of PM Samples — Each filter was cut into small pieces and the soluble organic fraction was extracted twice by ultrasonication with
$150 \mathrm{ml}$ of dichloromethane. The extract was filtered and evaporated to dryness with a rotary evaporator and a stream of nitrogen gas. The residue was dissolved in dimethyl sulfoxide (DMSO). Sample pretreatment was performed under darkroom conditions to prevent photochemical reactions.

Mutagenicity Assay — Mutagenicity assays of the samples were conducted in accordance with the preincubation technique ${ }^{19)}$ using the Salmonella typhimurium strain TA98. ${ }^{20)}$ As the mass of PM in each size-fraction was extremely small, assays were performed only without a metabolic activation system (S9 mix). Assays were carried out at three different dose levels. 2-Nitrofluorene was used as a positive control and DMSO was used as a solvent control.

\section{RESULTS AND DISCUSSION}

Figure 1(a) and 1(b) show particle size distributions of PM mass concentration at the roadside site and the suburban site, respectively. Figure 1 (c) shows the roadside/suburban ratio (R/S ratio) of PM mass concentration. Here, we refer to particles smaller than $0.12 \mu \mathrm{m}$ as ultrafine particles, those smaller than $2.1 \mu \mathrm{m}$ as fine particles (including ultrafine particles), and those larger than $2.1 \mu \mathrm{m}$ as coarse particles. In the ambient air at both sites, the particle size distributions of PM mass concentration were bimodal with peaks at the $0.50-0.70 \mu \mathrm{m}$ fraction and the $7.8-11 \mu \mathrm{m}$ fraction. The $\mathrm{R} / \mathrm{S}$ ratio of the PM mass concentration was close to 1.0 in the $0.2-1.2 \mu \mathrm{m}$ fractions, i.e., accumulation mode, while a high $\mathrm{R} / \mathrm{S}$ ratio was found in each size fraction of ultrafine particles and coarse particles. In particular, the highest $\mathrm{R} / \mathrm{S}$ ratio (3.0) was observed in the ultrafine particle fraction. In general, the residence time of ultrafine particles in the ambient air is shorter than that of accumulation mode particles because ultrafine particles show high dry deposition velocity. ${ }^{21)}$ Therefore, the mass concentration of ultrafine particles is particularly high in the ambient air around emission sources of ultrafine particles. Motor vehicles emit heavily ultrafine particles..$^{22,23)}$ Therefore, the high mass concentration in the ultrafine particle fraction at the roadside site would be caused by motor vehicle emissions.

Figure 2(a) and 2(b) show particle size distributions of mutagenic activity per unit air volume (revertants $/ \mathrm{m}^{3}$ ) at the roadside site and the suburban site, respectively. Figure 2(c) shows the R/S ratio of 

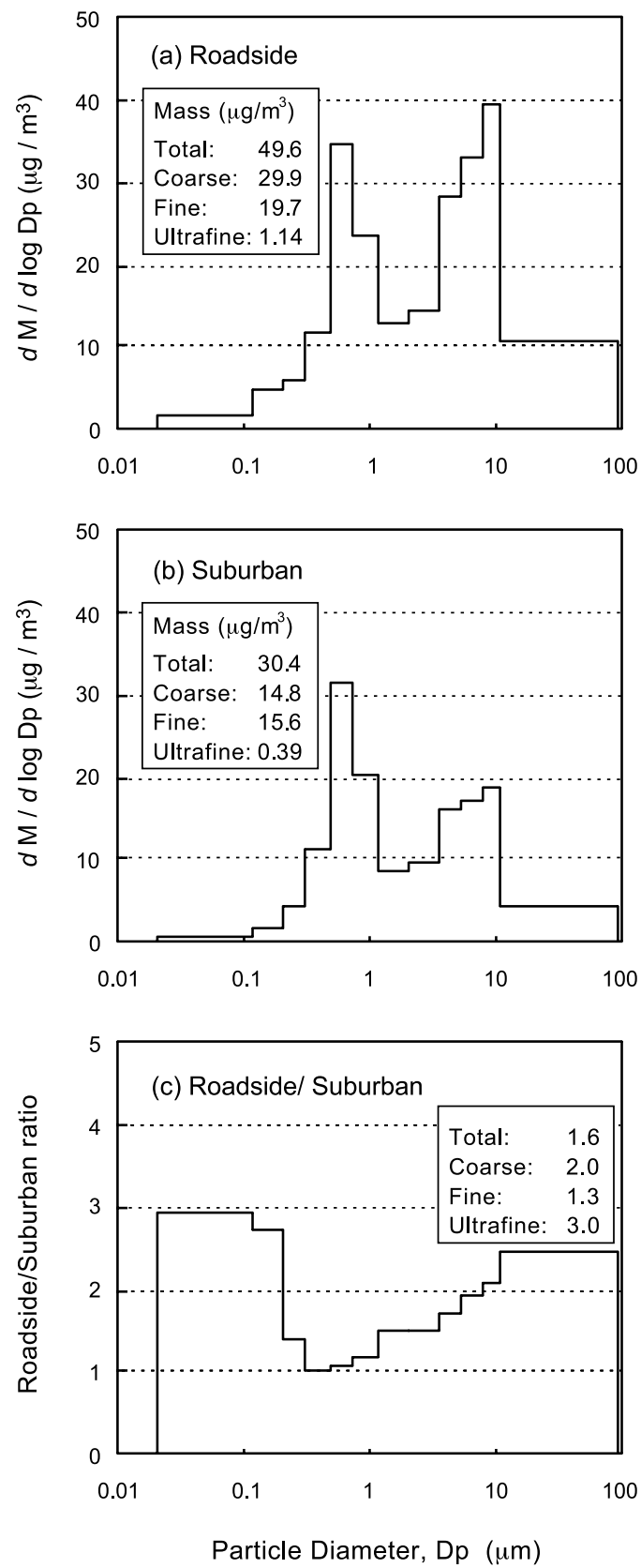

Fig. 1. Particle Size Distributions of PM Mass Concentrations at the Roadside Site and the Suburban site, and the Roadside/Suburban Ratio of PM Mass Concentration $\mathrm{M}=$ mass concentration, $\mathrm{Dp}=$ particle diameter.

the activity. All the size-fractionated PM samples showed direct-acting mutagenicity. The particle size distributions of the mutagenic activity per unit air volume were unimodal with a peak at the 0.50 $0.70 \mu \mathrm{m}$ fraction in the ambient air at both sites, although those of PM mass concentration were bimodal. Most of the mutagenic activity was found in the fractions of fine particles at both sites. Figure 3 shows the cumulative percentage (\%) of mass and
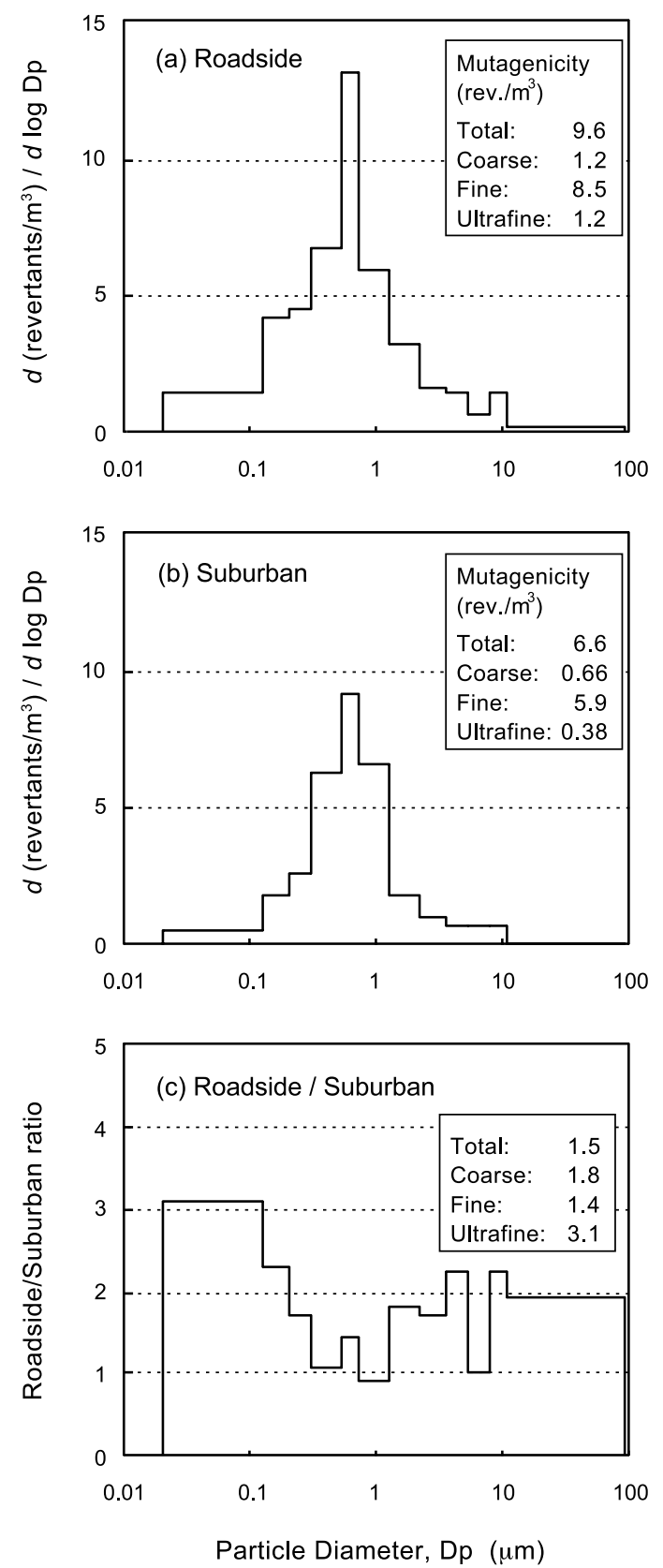

Fig. 2. Particle Size Distributions of the Mutagenic Activity per unit Air Volume (revertants $/ \mathrm{m}^{3}$ ) at the Roadside Site and the Suburban Site, and the Roadside/Suburban Ratio of the Activity

Mutagenicity assays were performed using the Salmonella typhimurium strain TA98 without S9 mix.

mutagenic activity (in revertants $/ \mathrm{m}^{3}$ ) of PM at the roadside site and the suburban site. The particle size distribution of the cumulative percentage is useful in considering the contributions of fine and ultrafine particles to the mutagenic activity of total PM. There was almost no difference in the mutagenic contribution of fine particles between the roadside site and 


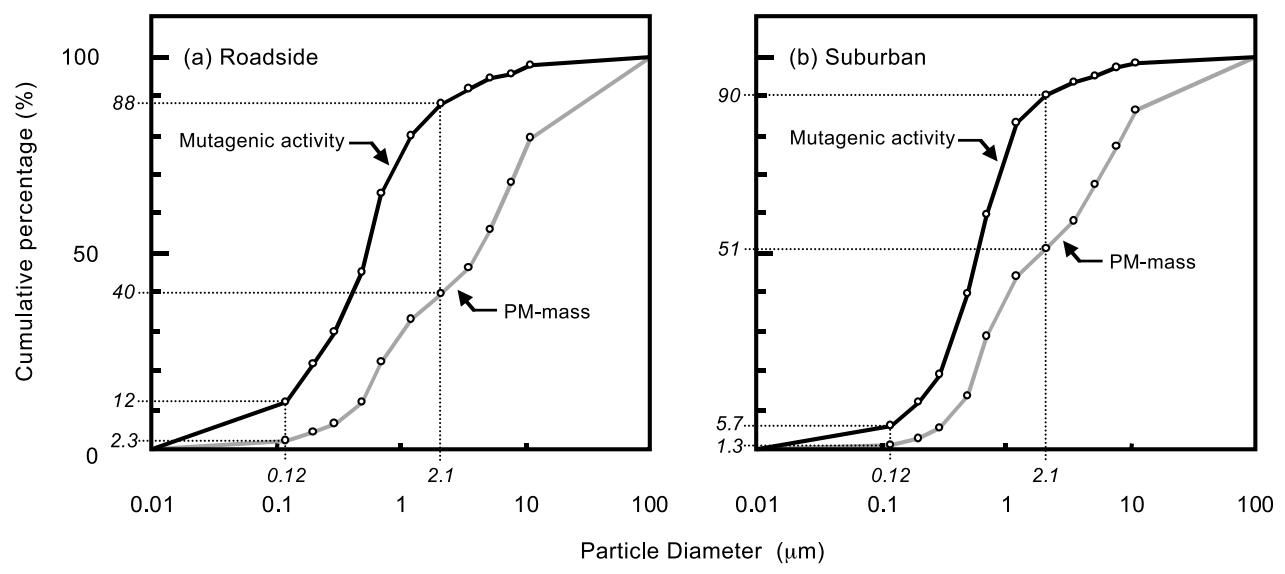

Fig. 3. Cumulative Percentage (\%) of the Mass and Mutagenic Activity of PM at the Roadside Site and the Suburban Site Mutagenicity assays were performed using the Salmonella typhimurium strain TA98 without S9 mix.

the suburban site. Fine particles contributed $88 \%$ to the mutagenic activity of total PM at the roadside site, and $90 \%$ to the activity at the suburban site. The dominance of the contribution of fine particles to the activity was in agreement with previous reports. ${ }^{10,13-15)}$

In contrast, there was a clear difference in the mutagenic contribution of ultrafine particles between the two sites. At the suburban site, ultrafine particles showed a contribution of $5.7 \%$ to the mutagenic activity of total PM. This percentage (5.7\%) was similar to that $(5.3 \%)$ at the suburban site in our previous study. ${ }^{17)}$ On the other hand, at the roadside site, ultrafine particles contributed as much as $12 \%$ to the mutagenic activity of total PM, although their contribution to the total PM mass was only $2.3 \%$. Moreover, as shown in Fig. 2, the mutagenic activity per unit air volume in the ultrafine particles fraction at the roadside site $\left(1.2\right.$ revertants $\left./ \mathrm{m}^{3}\right)$ was 3.1-fold higher than that at the suburban site $(0.38$ revertants $\left./ \mathrm{m}^{3}\right)$, although the mutagenic activity per unit air volume in the fine particle fractions at the roadside site $\left(8.5\right.$ revertants $\left./ \mathrm{m}^{3}\right)$ was only 1.4 -fold higher than that at the suburban site $\left(5.9\right.$ revertants $\left./ \mathrm{m}^{3}\right)$. As described previously, the main source of ultrafine particles at the roadside site is probably motor vehicle emissions. Exhaust particles from motor vehicles, particularly diesel motor vehicles, contain various direct-acting mutagenic compounds, such as nitro-PAHs and oxygenated nitro-PAHs. ${ }^{24-26)}$ Therefore, the higher mutagenic contribution and the higher mutagenic activity (in revertants $/ \mathrm{m}^{3}$ ) of the ultrafine particle fraction at the roadside site would be due to emissions from motor vehicles.

Figure 4 shows the mutagenic activity per unit

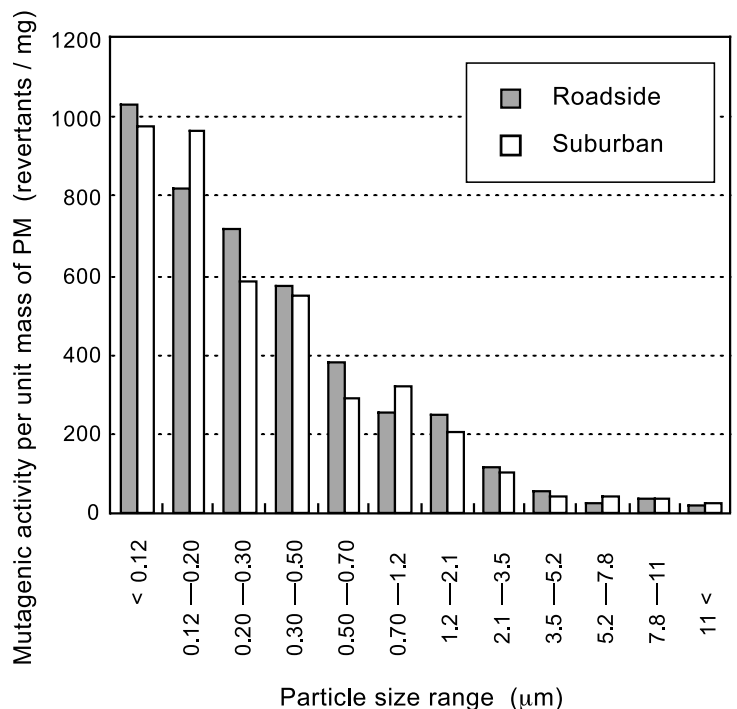

Fig. 4. Mutagenic Activity per unit Mass of PM (revertants/mg) in Each Size Fraction

Mutagenicity assays were performed using the Salmonella typhimurium strain TA98 without S9 mix.

mass of PM (revertants/mg) in each size fraction. The mutagenic activity per unit PM mass increased with decreasing particle size, and the highest activity (in revertants/mg) was observed in the ultrafine particle fraction at both sites. Ultrafine particles have a high surface area per unit PM mass. Therefore, ultrafine particles can likely adsorb significant amounts of mutagenic compounds on their surfaces.

There was almost no difference in the mutagenic activity per unit mass of PM in each fraction of ultrafine and fine particles between the roadside site and the suburban site (Fig. 4). This result indicates that the main sources of ultrafine particles and fine 
particles at the suburban site may be identical with those at the roadside site. That is, ultrafine particles in the exhaust of motor vehicles may greatly affect the mutagenic activity (in revertants $/ \mathrm{m}^{3}$ ) of the ultrafine particle fraction in the ambient air, not only at the roadside site, but also at the suburban site.

Ultrafine particles show much higher deposition efficiency to the pulmonary alveoli than fine particles and coarse particles, ${ }^{1)}$ and some of the inhaled ultrafine particles penetrate deeply into the cells and blood vessels of the lung ${ }^{3,4)}$ and the brain. ${ }^{5)}$ Moreover, as mentioned above, the mutagenic activity per unit mass of PM in the ultrafine particle fraction was significantly higher than those in the fine and coarse particle fractions at both sites. Thus, ultrafine particles may have a significant influence on human health, even if the contribution of ultrafine particles to the total PM mass is small. The results of the present study confirmed that the mass concentration and the mutagenic activity per unit air volume (revertants $/ \mathrm{m}^{3}$ ) in the ultrafine particle fraction at the roadside site were much higher than those at the suburban site. These results indicated that, with regard to the mutagenicity, the health risk due to ultrafine particles is relatively high at roadside areas. Future studies will need to investingate the relationship between the chemical composition and the mutagenic activity of ultrafine particles and clarify the significant contributor to the mutagenic activity of ultrafine particles.

\section{REFERENCES}

1) Heyder, J., Gebhart, J., Rudolf, G., Schiller, C. F. and Stahlhofen, W. (1986) Deposition of particles in the human respiratory tract in the size range 0.005-15 $\mu \mathrm{m}$. J. Aerosol Sci., 17, 811-825.

2) Yeh, H. C., Muggenburg, B. A. and Harkema, J. R. (1997) In vivo deposition of inhaled ultrafine particles in the respiratory tract of Rhesus monkeys. Aerosol Sci. Technol., 27, 465-470.

3) Ferin, J., Oberdöster, G. and Penney, D. P. (1992) Pulmonary retention of ultrafine and fine particles in rats. Am. J. Respir. Cell Mol. Biol., 6, 535-542.

4) Stearns, R. C., Murthy, G. G. K., Skornik, W., Katler, M. and Goldeski, J. J. (1994) Detection of ultrafine copper oxide particles in the lungs of hamsters by electron spectroscopic imaging. ICEM 13, Paris, 1722.

5) Oberdörster, G., Sharp, Z., Atudorei, V., Elder, A., Gelein, R., Kreyling, W. and Cox, C. (2004) Translocation of inhaled ultrafine particles to the brain.
Inhal. Toxicol., 16, 437-445.

6) Tokiwa, H., Morita, K., Takeyoshi, H., Takahashi, K. and Ohnishi, Y. (1977) Detection of mutagenic activity in particulate air pollutants. Mutat. Res., 48, 237-248.

7) Arey, J., Zielinska, B., Harger, W. P., Atkinson, R. and Winer, A. M. (1988) The contributions of nitrofluoranthenes and nitropyrenes to the mutagenic activity of ambient particulate organic matter collected in Southern California. Mutat. Res., 207, 4551.

8) Kameda, T., Sanukida, S., Inazu, K., Hisamatsu, Y., Maeda, Y., Takenaka, N. and Bandow, H. (2004) Association of the mutagenicity of airborne particles with the direct emission from combustion processes investigated in Osaka, Japan. Atmos. Environ., 38, 6937-6945.

9) Schnelle, J., Jänsch, T., Wolf, K., Gebefügi, I. and Kettrup, A. (1995) Particle size dependent concentrations of polycyclic aromatic hydrocarbons (PAH) in the outdoor air. Chemosphere, 31, 3119-3127.

10) Hayakawa, K., Kawaguchi, Y., Murahashi, T. and Miyazaki, M. (1995) Distributions of nitropyrenes and mutagenicity in airborne particulates collected with an Andersen sampler. Mutat. Res., 348, 57-61.

11) Jinhui, X. and Lee, F. S. C. (2000) Quantification of nitrated polynuclear aromatic hydrocarbons in atmospheric particulate matter. Anal. Chim. Acta, 416, 111-115.

12) Kawanaka, Y., Wang, N., Yun, S. J. and Sakamoto, K. (2002) Size distributions and seasonal variations in concentrations of 1-nitropyrene and polycyclic aromatic hydrocarbons in atmospheric particulate matter. J. Environ. Chem., 12, 599-607 (Japanese).

13) Talcott, R. and Harger, W. (1980) Airborne mutagens extracted from particles of respirable size. Mutat. Res., 79, 177-180.

14) Tokiwa, H., Kitamori, S., Takahashi, K. and Ohnishi, Y. (1980) Mutagenic and chemical assay of extracts of airborne particulates. Mutat. Res., 77, 99-108.

15) Pagano, P., De Zaiacomo, T., Scarcella, E., Buruni, S. and Calamosca, M. (1996) Mutagenic activity of total and particle-sized fractions of urban particulate matter. Environ. Sci. Technol., 30, 3512-3516.

16) Endo, O., Sugita, K., Goto, S., Amagai, T. and Matsushita, H. (2003) Mutagenicity of sizefractioned airborne particles collected with Andersen low pressure impactor. J. Health Sci., 49, 22-27.

17) Kawanaka, Y., Matsumoto, E., Sakamoto, K., Wang, N. and Yun, S. J. (2004) Size distributions of mutagenic compounds and mutagenicity in atmospheric particulate matter collected with a low-pressure cascade impactor. Atmos. Environ., 38, 2125-2132.

18) Kleeman, M. and Cass, G. R. (1998) Source contributions to the size and composition distribution of 
urban particulate air pollution. Atmos. Environ., 32, 2803-2816.

19) Yahagi, T., Nagano, M. and Seino, Y. (1977) Mutagenicities of N-nitrosoamines on Salmonella. Mutat. Res., 48, 121-130.

20) Ames, N., McCann, J. and Yamasaki, E. (1975) Methods for detecting carcinogens and mutagens with the Salmonella/mammalian-microsome mutagenicity test. Mutat. Res., 31, 347-364.

21) Kerzel, M. and Berkowicz, R. (2004) Modelling the fate of ultrafine particles from exhaust pipe to rural background: an analysis of time scales for dilution, coagulation and deposition. Atmos. Environ., 38, 2639-2652.

22) Morawska, L., Bofinger, N. D., Kocis, L. and Nwankwoala, A. (1998) Submicrometer and supermicrometer particles from diesel vehicle emissions. Environ. Sci. Technol., 32, 2033-2042.

23) Ristovski, Z. D., Morawska, L., Bofinger, N. D. and
Hitchins, J. (1998) Submicrometer and supermicrometer particulate emission from spark ignition vehicles. Environ. Sci. Technol., 32, 3845-3852.

24) Schuetzle, D., Riley, T. L. and Prater, T. J. (1982) Analysis of nitrated polycyclic aromatic hydrocarbons in diesel particulates. Anal. Chem., 54, 265271.

25) Hayakawa, K., Butoh, M. and Miyazaki, M. (1992) Determination of dinitro-and nitropyrenes in emission particulates from diesel and gasoline engine vehicles by liquid chromatography with chemiluminescence detection after precolumn reduction. Anal. Chim. Acta, 266, 251-256.

26) Enya, T., Suzuki, H., Watanabe, T., Hirayama, T. and Hisamatsu, Y. (1997) 3-Nitrobenzanthrone, a powerful mutagen and suspended human carcinogen found in diesel exhaust and airborne particulates. Environ. Sci. Technol., 31, 2772-2776. 